\title{
COVID 19 in Pregnancy: Immunology Savior or Culprit
}

Brinderjeet Kaur

Department of Obstetrics and Gynecology, Santokba Durlabhji Memorial Hospital and Research Center, Jaipur, India.

Corresponding Author: Brinderjeet Kaur, Department of Obstetrics and Gynecology, Santokba Durlabhji Memorial Hospital and Research Center, Jaipur, India.

\section{Received date: June 02, 2021; Accepted date: August 21, 2021; Published date: September 25, 2021}

Citation: Kaur B., (2021) COVID 19 in Pregnancy: Immunology Savior or Culprit. J. Obstetrics Gynecology and Reproductive Sciences 5(8); DOI: $10.31579 / 2578-8965 / 074$

Copyright: (C) 2021, Brinderjeet Kaur, This is an open access article distributed under the Creative Commons Attribution License, which permits unrestricted use, distribution, and reproduction in any medium, provided the original work is properly cited.

\section{Abstract to COVID 19 infection in pregnant woman. \\ Key words- immunity; pregnancy and covid -19}

Corona pandemic has been a nightmare for health care, from the point of view of transmission, pathogenesis, diagnosis and treatment, everything in doldrums. Pregnancy in itself encompasses altered physiology, immunity and often is characterized by unpredicted bodily responses.

The short review is an attempt to summarize the knowledge gained so far in context with COVID 19 infection in pregnancy. The paper highlights gaps in our present understanding and emphasize on more research for understanding the double edged sword - immune system and its response

\section{Introduction}

The information pertaining to pregnancy and COVID-19 infection remains limited and controversial. COVID -19 has been proclaimed as a global pandemic respiratory disease caused by severe acute respiratory syndrome corona virus 2 (SARS-CoV-2) [1].The viral infection has been reported to have three stages. Stage 1 - The incubation period where in most of the cases are asymptomatic however the virus survives in the host undetected butinfective. The incubation period from the day is usually of 5-7 days. Stage II - The virus is detectable with minor or mild symptoms like fever, cough, sore throat, myalgia, and fatigue [2-5].Stage III This is the full blown disease with cytokine storm manifesting with symptoms like high fever with coughing, headache, difficulty in breathing, pneumonia, diarrhea, haemoptysis and excessive sputum .Stage III can be divided into severe stage- defined as tachypnoea $>30$ breaths per minute, oxygen saturation $\leq 93 \%$ at rest , or $\mathrm{PaO} 2 / \mathrm{FiO} 2$ ratio $<300$ $\mathrm{mmHg}$ and criticalstage characterized by- respiratory failure requiring mechanical ventilation, septic shock or other organ dysfunction [6]. This critical stage requires intensive care. The current understanding of COID19 pathogenesis and clinical spectrum points out that individuals $>65$ years, with compromised immune system, other underlying chronic disease like diabetes mellitus or chronic infections and perhaps pregnant comprise the vulnerable group [7].

\section{Immune response in normal pregnancy}

Pregnancy has been described as physiologically altered inflammatory state $[8,9]$. The immune system behaves like a pendulum between proinflammatory to anti-inflammatory state during the various stages of pregnancy. The first trimester is pro -inflammatory and second trimester been anti -inflammatory and third trimester shifts back into pro inflammatory state [9]. An inflammatory response is triggered for the blastocyst to successfully penetrate the uterus for implantation and placentation during first trimester [10]. At this stage the maternal system weakens and mother suffers from morning sickness, weakness, fatigue, headache indicating pro-inflammatory phase [11]. In the second trimester maternal health improves and anti-inflammatory state leading to fetal development and growth swiftly. In the third trimester, the development of fetus completes and immune response is again activated for the delivery of the baby and the placenta [12], as the immune cells invade the myometrium with the pro -inflammatory phase facilitates contraction in the uterus [13].

It is important to take into consideration the role of NK cells. These NK cells protect the body from diseases by secreting cytokines such as INF $\gamma$ and $\mathrm{TNF} \alpha$, which act on other immune cells like macrophages to fight the infection .NK cells are controlled by inhibitory receptors such as NKG2A. Activation of NKG2A receptors prevent NK cells from destroying trophoblast cells [14, 15, and 16]. In a normal healthy pregnancy, the percentage of NK cells in the peripheral blood tend to increase in the first trimester, decrease in second and third trimester. The uterine NK cells during the first trimester become progressively less granular and decrease in number, leaving only minimal Uterine NK cells at term. Uterine NK cells are known to regulate trophoblast invasion by producing the chemokinesinterlukin (IL-8) and IFN -inducible protein (IP-10) and induce vascular growth by secreting angiogenic factors [17]. However, increased activation of uterine $\mathrm{NK}$ cells have been associated with pregnancy complications such as spontaneous abortion and pre-eclampsia [15].

\section{Pathogenesis in COVID-19}

The structure of COVID-19 has been described as a positive single stranded RNA genome having four genes; a spike protein, an envelope, a 
membrane and a nucleocapsid. [18] The main target of the virus is the pulmonary system where the virus binds to the host receptor, the angiotensin converting enzyme 2 (ACE 2) via receptor binding domains present on surface of epithelia cells [16]. The spike protein then undergoes a conformational modification for the viral envelope to bind to the cell membrane and release RNA into the host cells. Once RNA enters the host cell, it gets translated into viral replicases, which are split into smaller particles by enzymes called proteinases. The particles are then translated into viral proteins by mRNA and gather into virions on the endoplasmic reticulum and the Golgi apparatus where they are released out of the cells via vesicles [19]. Following their release, they enter the alveoli cells, endothelial cells and blood cells .This causes exaggerated activation of immune cells and cytokines.

\section{Corona virus immune response}

Studies have revealed that COVID -19 is characterized by increased total neutrophils, reduced total lymphocytes, increased IL-6, increased Creactive, D-dimer and Procalcitonin are indicate severe COVID-19 infection [4]. The latter findings also correlate with disease severity and death. A study by Evangelos et al investigating the immune response revealed that patients with severe respiratory failure displayed either macrophage activation syndrome (MAS) or very low human leucocyte antigen D related (HLA -DR )expression accompanied by profound depletion of CD4 lymphocytes, CD 19 lymphocytes , and natural killer (NK cells) [20]. Both NK cells and T cells (cell mediated cytotoxic adaptive immunity) are important for control of infection, their depletion is associated with severe COVID-19 infection [21]. Literature studies have noticed an increased expression of $\mathrm{NKG} 2 \mathrm{~A}$, which is an inhibitory receptor for NK. [21, 22]

\section{Similarity in immune response between corona infection and pregnancy (table 1)}

Proinflammatory cytokines such as IL -1 , IL-6, INF $\gamma$, MCP 1 and IP-10 have been reported to be elevated into the blood of patients infected by COVID -19 (5). Patients with severe disease show significantly higher percentage of CD 14, CD 16 inflammatory monocytes in peripheral blood than patients with mild disease. These cells secrete inflammatory cytokines that contribute to the cytokine storm, including MCP1, IP-10 and MIP1 $\alpha$, TNF $[5,7]$.The ripple of cytokines may result in septic shock, multi organ failure which may result in myocardial damage and circulatory failure observed in some patients. [22]

The pregnancy during first and second trimester is a pro inflammatory state more so in the I trimester. Therefore the risk of contracting COVID19 infection is higher in I trimester. Immune defense in I trimester is governed by activation of NK cells and monocytes at one end and attenuation of cell mediated The 1 immunity with predominance of Th2 dominated environment that increases morbidity due to infection. [24]

Corona virus is known to target the host receptor ACE 2 via receptor binding domain. The expression of ACE 2 in the placenta is higher in the villous cytotrophoblast, syncitiotrophophoblast cells in the deciduas during the the first trimester of the pregnancy (25). Since ACE 2 is highly expressed in this region of the placenta, this not only increases the risk of the mother contracting SARS-CoV -2 , but this is also plausible cause that transmission from the mother to child may occur .(26) Till now , no reports on mother to child transmission of the coronavirus have been reported. In fact this transmission is highly unlikely since placenta creates a protective mechanism against viruses .The placenta actually creates protection against foreign pathogens by anti-microbial action .[23] The trophoblast cells stimulate the expression of secretory leucocyte protease inhibitor (SLPI) and INF- 3 , which are recognized for inhibitory action against viruses. .

\begin{tabular}{l}
\hline Pregnancy \\
$\downarrow$ Natural Killer Cells \\
$\uparrow$ NKG2A Receptors \\
$\downarrow$ Lymphocytes \\
$\uparrow$ Pro inflammatory factors \\
$\uparrow$ ACE 2 Receptors \\
\hline
\end{tabular}

\begin{tabular}{l} 
COVID -19 Infection \\
$\downarrow$ Natural Killer Cells \\
$\uparrow N K G 2 A$ Receptors \\
$\downarrow$ Lymphocytes \\
$\uparrow$ Pro inflammatory factors \\
$\uparrow A C E 2$ Receptors \\
\hline
\end{tabular}

COVID -19 Infection

$\downarrow$ Natural Killer Cells

$\uparrow N K G 2$ A Receptors

$\uparrow$ Pro inflammatory factors

$\uparrow$ ACE 2 Receptors

Table -1 The immune response in Normal Pregnancy vs COVID -19

Pregnancy brings mechanical effects on physiological cardio respiratory system alterations causing diaphragmatic displacement by the gravid uterus and the gestational weight gain resulting in altered pulmonary volumes leading to reduced total lung capacity and to an inability to clear effectively the pulmonary secretions. (27) This could add to susceptibility to infection.

\section{Factors lowering the risk of infection in pregnancy}

Inspite of the much publicized increased risk of pregnant women, the reports of inflammatory lung process towards extensive tissue damage and the ARDS has been rarely observed. The speculated explanation could be physiological "silencing "of the Th 1 pro -inflammatory response and dominance of Th 2 over Th 1 immunity which may account for a more restrained inflammatory cascade in pregnant women with COVID19. While the Th1 lymphocyte cytokines include gamma interferon (IFN $-\gamma$ ), interleukin IL-1 $\alpha$, IL-1, IL-12, IL-6 are microbicidal and proinflammatory. On the contrary in Th 2 dominated pregnancy state anti -inflammatory response is mediated by IL-, IL-10, IL-13 and transforming growth factor beta (TGF) [28, 29].

It is also possible that pregnancy been dominated by anti-inflammatory milieu which makes the immune response less deregulated and blunt the fatal cytokine storm which would have otherwise set in by the Th 1 cells.
On this ground, it may be explained why hydrochloroquine (HCQ), colchicines, monoclonal antibody anti- IL1R (Tolclimuzab and Anakinra ) have been documented to mitigate the inflammatory response and provide clinical benefits. Hydroxychloroquine, Colchicine and Tolclimuzab have ability to reduce IFN-Y and IL-1 secretion by inhibition of IL-6 receptors. (28) Heparin use is all supported due to its anti inflammatory action which may further decrease the risk of arterial and venous thrombosis. [29]

\section{Conclusion}

We may infer from above discussion that COVID-19 infection and pregnancy has few similar immunological responses. The I and II trimester of pregnancy are more susceptible to COVI19 disease. The current literature does not establish vertical maternal to child transmission of COVID-19 infection and therefore it can be concluded overall COVID19 infection in pregnancy follows a benign course with less likelihood of cytokine storm or grave COVID-19 complications. Further studies on immunological aspects of COVID-19 infection in pregnant woman are required for enhancing our knowledge on this bewildering aspect of immunity, a double edged sword.

Sources of funding -Nil 


\section{Conflict of interest- Nil}

\section{References}

1. Organization WH. (2019) Coronavirus disease (COVID) : situation report 2020; vol 72

2. Chan JF, W Yuan S, Kok K, H To, W Chu, Yang J , et al . (2020) A familial cluster of pneumonia associated with the novel coronavirus indicating person -to - person transmission: a study of a family cluster. Lancet; 395(10223): 514-23.

3. Chen N, Zhou M, Dong X, Qu J, Gong F, Han Y, et al . (2020) Epidemological and clinical characteristics of 99 cases of 2019 novel coronavirus pneumonia in Wuhan. China: a descriptive study Lancet (2020) 395(10223) : 507-13 .

4. W. j Guan, Ni Z.y, Liang W-h, C-q Ou, HeJ x , et al (2020) Clinical characteristics of coronavirus disease 2019 in China . N Engl J Med 2020:382 1708-20.

5. Huang C, Wang Y, Li X, Ren I, ZhaoJ, Ha Y, et al. (2020) Clinical features of patients infected with 2019 novel coronavirus in Wuhan, China. Lancet ;395(10223):495-506

6. Surveillances V. (2020) The epidemiological characteristics of an outbreak of 2019 novel coronavirus diseases (COVID -19)China CDC Wkly; 2(8):113-22.

7. Rothan HA, Byrareddy SN. (2020) The epidemiology and pathogenesis of coronavirus disease (COVID-19 )outbreak $J$ Autoimmun; 102433

8. WegmannT.Foetal protection against abortion: is it immunosuppresion or immunomodulation? Ann Inst Pasteur /Immunol 1984; 135(3)309-12 editor, Elsevier.

9. Wegmann TC, Lin H, Guilbert I, Mosmann TR. Bidirectional cytokine interactions in the maternal -fetal relationship: is successful pregnancy a $\mathrm{TH} 2$ phenomenon? Immunol Today 1993; 14(7):353-6.

10. Dekel N, Gnainsky Y, Granot I, Mor C. Inflammation and implantation. Am J ReprodImmunol 2010; 63(1):17-21.

11. Mor C, Abrahams VM. Immunology of implantation. Immunol Allergy Clin N Am 2020; 22(3):545-65.

12. MorG,Cardenas . The immune system in pregnancy: a unique complexity . Am J ReprodImmunol 2010;63(6):425-33

13. Romero R, Espinoza J, Kusanovic JP, Gotsch F, Hassan S, Erez $\mathrm{O}$, et al . The preterm partiruition syndrome BJOG; Int $\mathbf{J}$ ObstetGynaecol $2006 ; 113: 17-42$.

14. Bachmayer N, Sohlberg E, Sundstrom Y, Hamad RR, Berg L, Bremme K . et al . Women with pre-eclampsia have an altered NKG2A and NKG2A receptor expression on peripheral blood natural killer cells . Am J ReprodImmunol 2009;62(3):147-57 .

15. Phoswa WN, Naicker T, Ramsuran V , Moodley J. Preeclampsia : the role of highly active antiretroviral therapy and immune markers . Inflamm Res 2019;68(1):47-57.
16. Wan Y,Shang J, Graham R, Baric RS , Li F. Receptor recognition by the novel coronavirus from Wuhan : an analysis based on decade -long structural studies of SARS coronavirus J Virol 2020;94(7)

17. Hanna J, Goldmann-Wohl D, Hamani Y, Avraham I, Greenfield C, Natanson - Yaron S, et al. Decidual NK cells regulate key developmental processes at the human fetal maternal interface . Nat Med 2006; 12(9):1065-74.

18. Chen Y, Liu Q, Guo D. (2020) Emerging coronaviruse: genome structure, replication, and pathogenesis. J Med Virol ; 92(4):418-23.

19. Shereen MA, Khan S, Kazmi A, Bashir N, Siddique R. (2020) COVID -19 infection :origin, transmission, and characteristics of human coronaviruses. $J$ Adv Res;2:91-8

20. Giamaellos -BourboulisEJ , Netea MG , Rovina N , Akinosoglou K, Antoniadou A, Antonakos N, et al(2020) Complex immune dysregulation in COVID-19 patients with severe respiratory failure . Cell Host Microbe;27(6) 992-1000 e3.

21. Zheng M, Gao Y, Wang G,Song G, Liu S , Dun D et al . (2020) Functional exhaustion of antiviral lymphocytes in COVID -19 patients. Cell Mol Immunol;1-3.

22. Ruan Q, Yang K, Wang W et al (2020) Clinical Predictors of mortality due to COVID -19 based on analysis of data of 150 patients from Wuhan, China Intensive Care Med;1-3.

23. Mor G, Cardenas I. (2010). The immune system in pregnancy: a unique complexity .Am J ReprodImmunol 63 (6):425-33.

24. Aghaeepour N, Ganio EA, Mcilwain D, Tsai SA, Tingle M, Van Gassen et al . (2017) An immune clock of human pregnancy. SciImmunol ;2 (15)

25. Turco MY, Moffett A. (2019) Development of the human placenta. 16-(22)

26. Li M, Chen I,Zhang J, Xiong C, Li X.(2020) The SARS-CoV 2 receptor ACE2 expression of maternal -fetal interface and fetal organs by single cell transcriptome study. PLoS One ;15(4)e0230295.

27. Mahase E, (2020) COVID -19:most patients require mechanical ventilation in first 24 hours of critical care .BMJ2020:368:m 1201doi

28. Dashraath P, Jing Lin JeslynW,Mei Xian Karen I, Li Min Lim , Li S. Biswas A et al. Coronavirus Disease 2019 (COVID-19 )Pandemic and Pregnancy Am J ObstetGynecol;S00029378(20):3033-4

29. McGonag, Le D, Sharif K, O’Regan A, Bridgewood C. (2020) The role of cytokines including interlukin-6 in COVID -19 induced pneumonia and macrophage activation syndrome -like disease Autoimmune Rev 2020;102537.
This work is licensed under Creative Commons Attribution 4.0 License

To Submit Your Article Click Here: Submit Manuscript

DOI: $10.31579 / 2692-9759 / 028$

$$
\begin{aligned}
& \text { Ready to submit your research? Choose Auctores and benefit from: } \\
& \text { - fast, convenient online submission } \\
& \text { raporous peer review by experienced research in your field } \\
& \text { * authors retain copyrights } \\
& \text { - imique DOI for all articles }
\end{aligned}
$$

At Auctores, research is always in progress.

Learn more www.auctoresonline.org/journals/cardiology-research-andreports 